\title{
PREDIÇÃO ESPACIAL DAS CARACTERÍSTICAS DE PRODUÇÃO DE Urochloa brizantha cv. MARANDU
}

Ademar Roberto Gross Filho ${ }^{1}$, Rafael Nunes Garcia ${ }^{1}$, Alessandra Farias da Silva ${ }^{2}$, Mateus da Silva Penno $^{3}$, Sabino Pereira da Silva Neto ${ }^{4}$

\section{RESUMO}

Os ambientes pastoris, naturalmente, são heterogêneos por causa, por exemplo, do pastejo desuniforme dos bovinos. A caracterização da disposição espacial da biomassa aérea, de uma pastagem, pode ser realizada por meio da geoestatística. Entretanto, para que o semivariograma tenha alguma confiabilidade é necessário um número suficiente de amostras. O objetivo foi verificar a influência da densidade amostral na construção e exatidão dos semivariogramas das características de produção em uma pastagem de Urochloa brizantha cv. Marandu. As coletadas da biomassa das plantas foram realizadas em malhas amostrais compostas por 30, 60, 90, 120 e 150 pontos de uma área de $14.400 \mathrm{~m}^{2}$ (120x120 m). A produção de massa seca de folhas verdes, colmo e material morto da pastagem foram submetidos às análises de estatística descritiva e ao estudo geoestatístico e interpolação por krigagem ordinária. A variabilidade espacial das características produtivas da gramínea foi observada em todos os planos amostrais utilizados. Os melhores ajustes do semivariograma foram conseguidos quando se utilizou 120 e 150 pontos de amostra. Assim, pode-se utilizar no mínimo 120 pontos de amostras para realizar estudos da variabilidade espacial das características agronômicas de pastagens de Urochloa brizantha cv. Marandu.

Palavras-chave: estrutura do pasto, semivariograma, variabilidade espacial, zootecnia de precisão

\section{ABSTRACT \\ SPATIAL PREDICTION OF THE PRODUCTION CHARACTERISTICS OF Urochloa brizantha cv. MARANDU}

Environments the pastoris, are heterogeneous, for example, uneven grazed of cattle. The spatial arrangement of biomass characterization of grassland, may be performed by geostatistical. However, for the semivariogram has some reliability the number required of samples sufficient. The objective of this study was investigated the influence of sample density in the construction and accuracy of semivariograms from production characteristics of Urochloa brizantha cv. Marandu. The collected biomass of the plants was held in grid comprising 30, 60, 90, 120 e 150 sample points from an area of 14,400 $\mathrm{m}^{2}(120 \times 120 \mathrm{~m})$. The dry matter yield of green leaves, stem and dead material grassland were submitted to descriptive statistical analysis, to study and geostatistical interpolation by ordinary kriging. The spatial variability of production characteristics of grass was observed in all sampling plans used. The semivariogram best fits were obtained when using 120 and 150 sample points. Thus, it can be used at least 120 points samples to conduct studies of the spatial variability from agronomic characteristics of Urochloa brizantha cv. Marandu.

Keywords: precision animal science, semivariogram, spatial variability, structure pasture

\section{Recebido para publicação em 25/09/2015. Aprovado em 29/08/2016.}

1 - Técnico em Agronegócio, Discente de Engenharia Civil da UNIRG/Gurupi - TO, ademar.gross@hotmail.com

2 - Técnica em Agronegócio, Discente de Letras da UNB/Brasília - DF, alessandra-faria@live.com

3 - Discente de Medicina Veterinária da Faculdade Católica do Tocantins/Palmas - TO, mateuspenno@hotmail.com

4 - Zootecnista, Docente do IFTO/Gurupi - TO, sabino.pereira@ifto.edu.br

\section{REVENG} 406-416p. 


\section{INTRODUÇÃO}

As interações dos animais em pastejo com o recurso alimentar são afetadas pela estrutura do pasto (PALHANO et al., 2006). Essas modificações dos padrões de deslocamento e procura de forragem, são induzidas por qualquer variável espacialmente dependente, que por sua vez, interferem no desempenho dos animais e na eficiência de uso da pastagem (PÁSCOA \& COSTA, 2007). A variabilidade espacial da biomassa aérea de uma pastagem define a estrutura do pasto. Esta heterogeneidade espacial é, entre outros fatores, devido ao pastejo desuniforme dos bovinos (SALTON \& CARVALHO, 2007). Assim, é necessário compreender a estrutura do pasto $\mathrm{e}$ sua relação com a forragem produzida e consumida pelos animais para, então, fundamentar ações de manejo que possam ser racionais e sustentáveis (GONÇALVES, et al. 2009).

A heterogeneidade do pasto pode ser inferida por meio da modelagem dos padrões espaciais e então estimados valores em locais não observados ou amostrados. Para isso, a dependência espacial do pasto deve ser representada pelo semivariograma que é a ferramenta central da geoestatística. Apesar disso, nem sempre os semivariogramas são robustos e/ou precisos, devido à influência do número de amostras e escolha do modelo que melhor se ajuste aos dados da semivariância experimental.

As somas necessárias para o cálculo da semivariância devem ser constituídas por um número suficiente de pares, que tornem o resultado consistente (LANDIM, 2006). De acordo com Webster \& Oliver (1992), a construção do semivariograma para situações típicas de levantamentos do solo e de variáveis ambientais necessita de uma quantidade mínima de 50 pontos de amostragem para gerar semivariogramas com alguma confiabilidade. No entanto, as estimativas do semivariograma experimental são mais precisas com a utilização de pelo menos 100 pontos amostrais (WEBSTER \& OLIVER, 1992). Já Landim (2006) sugere que, para uma análise geoestatística, o número mínimo de pontos amostrados, considerado razoável, é de 30 a 40 pontos.

A eficiência do arranjo amostral permite descrever bi ou tridimensionalmente um ambiente tão complexo, como o pasto. Neste contexto, objetivou-se verificar a influência da densidade amostral na construção e exatidão dos semivariogramas a partir das características agronômica de uma pastagem de Urochloa brizantha cv. Marandu.

\section{MATERIAL E MÉTODOS}

O trabalho foi conduzido na Fazenda MR, município de Cariri do Tocantins - TO. O local de estudo está situado na latitude, $11^{\circ} 49^{\prime}$ '54" $\mathrm{S}$ e longitude $49^{\circ}$ 6' $54^{\prime \prime} \mathrm{W}$. De acordo com a classificação de Köppen (1948), a região apresenta clima tipo Aw (quente úmido), com temperatura média de $28^{\circ} \mathrm{C}$ e precipitação pluviométrica média de $1.500 \mathrm{~mm}$ anuais. O solo da área é classificado como Latossolo Vermelho Amarelo Distrófico (EMBRAPA, 2006).

A área experimental foi composta de um piquete, com pastagem de Urochloa brizantha $\mathrm{cv}$. Marandu, utilizado em sistema de lotação contínua, estabelecido no ano de 2010. Neste piquete foi demarcada uma área de $14.400 \mathrm{~m}^{2}(120 \times 120$ $\mathrm{m})$ onde foram definidos pontos de coletas com densidade amostral de 30, 60, 90, 120 e 150 (Figura 1). Em cada ponto de amostragem pré-estabelecido realizou-se a coleta da gramínea com quadro de amostragem de $0,5 \mathrm{~m}^{2}(0,5 \times 1,0 \mathrm{~m})$. A gramínea foi colhida à altura de $15 \mathrm{~cm}$ do solo e colocada em sacos identificados, levados para pesagem e separação manual dos componentes morfológicos (folhas verdes, colmo + bainha foliar e material morto). Em seguida, esses componentes foram acondicionados em sacos de papel identificados, e levados à estufa para secagem a $65^{\circ} \mathrm{C}$ por 72 horas ou até peso constante. Após secagem as amostras foram pesadas e determinadas as produções de massa seca de folhas (MSF), massa seca de colmo (MSC) e massa seca de material morto (MSMM) expressas em $\mathrm{g} \mathrm{m}^{-2}$.

Os dados das produções de biomassa das gramíneas foram submetidos à análise exploratória, para verificar a aleatoriedade e agregação através dos cálculos de média, mínimo, máximo e dos coeficientes de assimetria, curtose e de variação, bem como, o tipo de distribuição. Utilizou-se o teste 


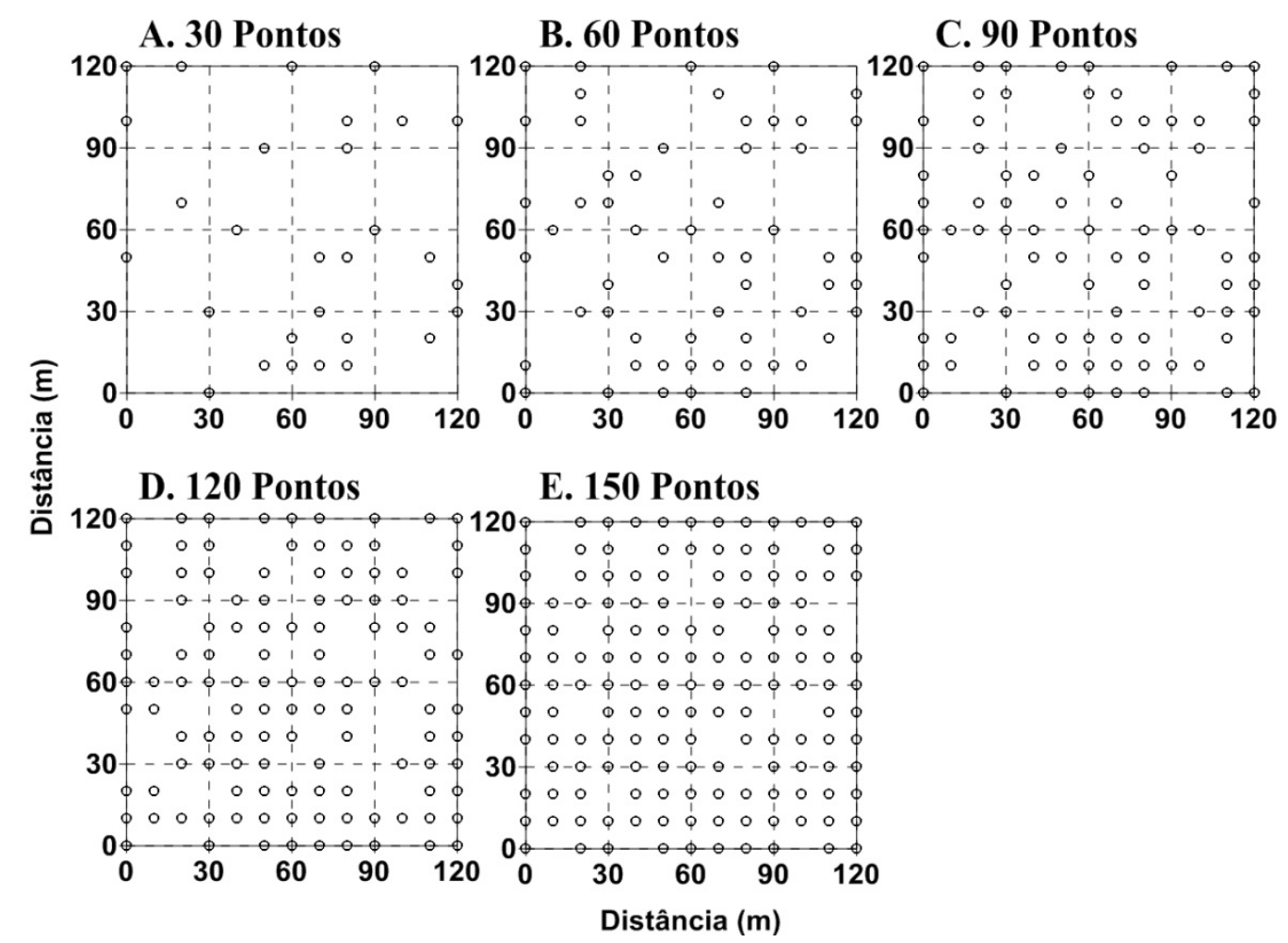

Figura 1. Esquema de coleta e densidade de amostragem da Urochloa brizantha cv. Marandu.

de Kolmogorov-Smirnov a 5\% de probabilidade para testar a hipótese de normalidade dos dados.

A estrutura da dependência espacial foi caracterizada por meio de análise geoestatística, calculando-se a semivariância com a equação 1 proposta por Matheron (1963):

$\tilde{\mathrm{a}}(\mathrm{h})=\frac{1}{2 \mathrm{~N}(\mathrm{~h})} \sum_{\mathrm{i}=1}^{\mathrm{N}(\mathrm{h})}\left[\mathrm{Z}\left(\mathrm{x}_{\mathrm{i}}\right)-\mathrm{Z}\left(\mathrm{x}_{\mathrm{i}}+\mathrm{h}\right)\right]^{2}$

Sendo $\mathrm{N}(\mathrm{h})$ o número de pares de valores experimentais medidos em $\left[\mathrm{Z}\left(\mathrm{x}_{\mathrm{i}}\right), \mathrm{Z}\left(\mathrm{x}_{\mathrm{i}}+\mathrm{h}\right)\right]$, separados pelo vetor $h$. No presente estudo, os valores de $Z$ são as características de produção do capim Marandu, enquanto os valores de $\mathrm{x}_{\mathrm{i}}$ e $\mathrm{x}_{\mathrm{i}}$ $+\mathrm{h}$ foram definidos de acordo com a localização geográfica das amostras realizadas na pastagem.

Nesse estudo, foram testados os modelos de semivariogramas: (a) esférico, $\gamma(\mathrm{h})=\mathrm{C}_{0}+\mathrm{C}_{1}[1,5$ $\left.(\mathrm{h} / \mathrm{A})-0,5(\mathrm{~h} / \mathrm{A})^{3}\right]$ para $(0<\mathrm{h} \leq \mathrm{A})$ e $\gamma(\mathrm{h})=\mathrm{C}_{0}+$ $\mathrm{C}_{1}$ para $\mathrm{h}>\mathrm{A}$; (b) exponencial, $\gamma(\mathrm{h})=\mathrm{C}_{0}+\mathrm{C}_{1}[1$ $\exp (-\mathrm{h} / \mathrm{A})]$; e (c) gaussiano, $\gamma(\mathrm{h})=\mathrm{C}_{0}+\mathrm{C}_{1}[1-\exp$ $\left.\left(-h^{2} / A^{2}\right)\right]$ em que "d" é a distância máxima na qual o semivariograma é definido e " $\mathrm{A}$ " o alcance. $\mathrm{O}$ ajuste dos semivariogramas possibilitou definir os valores do efeito pepita $\left(\mathrm{C}_{0}\right)$, do alcance $(\mathrm{A})$ e do patamar $\left(\mathrm{C}+\mathrm{C}_{0}\right)$.
Seguiu-se com a escolha do modelo ajustado dos semivariogramas, realizada com base na raiz quadrada do erro quadrático médio (RSME). Além disso, avaliou-se o desempenho de cada modelo por meio do critério de Akaike (AIC). Este critério é dado pela seguinte expressão: AIC $=-2 \log \mathrm{L}+$ $2 \mathrm{~K}$ em que $\mathrm{L}$ é a verossimilhança maximizada pelo modelo candidato e K é o número de parâmetros do modelo considerado.

Os mapas de contorno foram criados com a interpolação dos valores por meio de krigagem ordinária, de modo a definir o padrão espacial da biomassa da gramínea, utilizando-se o programa Surfer versão 8.0 (GOLDEN SOFTWARE, 2002) com o auxilio da equação 2 :

$Z *\left(x_{0}\right)=\sum_{i=1}^{N} \lambda_{i} Z\left(x_{i}\right)$

em que,

$\mathrm{Z} *\left(\mathrm{x}_{0}\right)$ é a variável biomassa da gramínea (MSFV, MSC e MSMM), $\lambda_{i}$ é o peso da i-ésima localidade vizinha; $\mathrm{Z}\left(\mathrm{x}_{\mathrm{i}}\right)$ é o valor da variável para a i-ésima localidade e $\mathrm{N}$ é o número de localidades vizinhas empregadas para interpolação do ponto (VIEIRA, 2000).

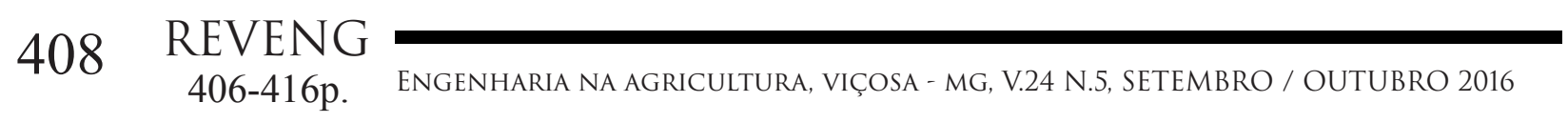




\section{RESULTADOS E DISCUSSÃO}

A análise descritiva geral dos dados indicou que os valores de mínimo e máximo, da massa seca dos componentes morfológicos, se situam bem distantes, independentes da quantidade de pontos amostrais (Quadro 1). Ao investigar os resultados do teste de normalidade de Kolmogorov-Smirnov, notou-se que somente quando utilizado 30 pontos amostrais foi obtida distribuição normal para todas as variáveis analisadas.

A oferta de massa de forragem naturalmente é heterogênea espacialmente, devido ao pastejo desuniforme dos bovinos (SALTON \& CARVALHO, 2007) ou mesmo em função dos padrões espaciais da deposição de fezes (SILVA NETO et al., 2011a) e dos atributos físicos e químicos do solo (GREGO et al., 2012). Essa variabilidade horizontal do pasto pode ser descrita pelo coeficiente de variação (CV) (HIRATA, 2002). Assim, os valores de CV dos planos amostrais investigados nesse presente experimento indicam que os dados da massa seca de forragem apresentam, na maioria dos casos, média variação espacial (WARRICK \& NIELSEN, 1980). Essa mesma situação já foi observada em estudo da variabilidade espacial da gramínea em pastagens de capim Marandu (SILVA NETO et al., 2012).

Os valores de $\mathrm{CV}$, apesar de indicar a ocorrência de determinado grau de heterogeneidade do pasto, não são capazes de descrever a sua estrutura espacial, bem como prever onde os animais poderiam pastejar em decorrência dessa variabilidade. Assim, a caracterização da distribuição espacial torna-se importante, visto que, bovinos em pastagens heterogêneas mudam suas estratégias de busca por alimento como tentativa de aumentar ou mesmo manter a eficiência de consumo de forragem (MEZZALIRA et al. 2013). Neste contexto, a utilização de valores médios não permite distinguir adequadamente os níveis de oferta de biomassa da pastagem no plano horizontal e consequentemente não possibilita a previsão dos padrões de deslocamento e desempenho dos animais em pastejo.

Quadro 1. Estatística descritiva da massa seca de folhas (MSF), colmo (MSC) e material morto (MSMM) em pastagem de Urochloa brizantha cv. Marandu

\begin{tabular}{|c|c|c|c|c|c|c|c|}
\hline \multirow{2}{*}{ Tamanho da amostra } & \multirow{2}{*}{ Mínimo } & \multirow{2}{*}{ Média } & \multirow{2}{*}{ Máximo } & \multicolumn{3}{|c|}{ Coeficiente } & \multirow{2}{*}{ p-valor ${ }^{1}$} \\
\hline & & & & Variação & Curtose & Assimetria & \\
\hline \multicolumn{8}{|c|}{$\mathrm{MSF}^{2}$} \\
\hline 30 & 0,00 & 53,38 & 148,37 & 56,40 & 2,36 & 1,03 & $0,07^{*}$ \\
\hline 60 & 0,00 & 55,62 & 216,05 & 63,50 & 6,26 & 2,05 & $4 \times 10^{-5 * *}$ \\
\hline 90 & 0,00 & 55,47 & 216,05 & 59,10 & 6,34 & 1,75 & $0,004^{* *}$ \\
\hline 120 & 0,00 & 55,63 & 216,05 & 56,40 & 5,76 & 1,64 & $0,002^{* *}$ \\
\hline 150 & 0,00 & 55,85 & 216,05 & 53,30 & 5,75 & 1,61 & $0,001^{* *}$ \\
\hline \multicolumn{8}{|c|}{$\mathrm{MSC}^{3}$} \\
\hline 30 & 0,00 & 32,95 & 72,47 & 58,40 & $-0,58$ & 0,47 & $0,14^{*}$ \\
\hline 60 & 0,00 & 35,22 & 92,29 & 57,10 & $-0,20$ & 0,58 & $0,06^{*}$ \\
\hline 90 & 0,00 & 35,25 & 134,05 & 61,10 & 4,02 & 1,36 & $0,06^{*}$ \\
\hline 120 & 0,00 & 34,34 & 134,05 & 62,80 & 3,49 & 1,40 & $0,004^{* *}$ \\
\hline 150 & 0,00 & 35,65 & 134,05 & 58,60 & 2,85 & 1,19 & $0,002^{* *}$ \\
\hline \multicolumn{8}{|c|}{ MSMM $^{4}$} \\
\hline 30 & 0,00 & 45,18 & 100,64 & 48,10 & 0,88 & 0,67 & $0,15^{*}$ \\
\hline 60 & 0,00 & 47,04 & 157,02 & 59,10 & 3,12 & 1,50 & $0,001^{* *}$ \\
\hline 90 & 0,00 & 44,52 & 157,02 & 59,40 & 3,47 & 1,43 & $0,004^{* *}$ \\
\hline 120 & 0,00 & 43,27 & 157,02 & 57,40 & 3,62 & 1,41 & $0,003^{* *}$ \\
\hline 150 & 0,00 & 43,56 & 157,02 & 54,90 & 3,23 & 1,26 & $0,011^{* *}$ \\
\hline
\end{tabular}

${ }^{(1)}$ teste de normalidade de Kolmogorov-Smirnov, ${ }^{(*)}$ : significativo a $5 \%,{ }^{(* *)}$ : não-significativo a $5 \%$, ${ }^{(2)}$ MSF: massa seca de folhas, ${ }^{(3)}$ MSC: massa seca de colmo, (4)MSMM: massa seca de material morto. 
As cinco densidades amostrais, investigadas neste estudo, apresentaram padrão espacial que se ajustou, na maioria das vezes, ao modelo esférico (Quadro 2). A produção de massa seca de folhas (MSF), em todos os tamanhos amostrais, se ajustou ao modelo esférico. Já a produção de massa seca de colmo (MSC) se ajustou ao modelo gaussiano, quando utilizados números de amostra iguais a 30 , 60 e 120 pontos. Nos demais tamanhos amostrais ocorreram ajuste ao modelo esférico. Na produção de massa seca de material morto (MSMM), apenas no tamanho de amostra igual a 60 pontos foi verificado ajuste ao modelo gaussiano, enquanto os demais se ajustaram melhor ao modelo esférico.

Determinações da variabilidade espacial da massa seca de Brachiaria híbrida cv. Mulato II se ajustou matematicamente, no maior número de casos, ao modelo exponencial (PAULA NETO et al., 2014). Já para biomassa da pastagem de Urochloa brizantha, durante as estações de verão e outono, encontraram ajuste ao modelo esférico (GREGO et al., 2012). Entretanto, mais importante que o modelo é o grau de precisão desse em mapear a variabilidade do atributo investigado na área. Somente assim, a adoção da autocorrelação espacial seria justificável em relação às predições médias que normalmente são utilizadas para descrever o grau de heterogeneidade do pasto. Ressalta-se que esses padrões espaciais podem variar consideravelmente em função de alterações temporais nos fatores intrínsecos e extrínsecos, tais como: ambientais e de manejo da pastagem (SILVA NETO et al., 2011b).

Ao analisar a raiz quadrada do erro quadrático

Quadro 2. Modelos e parâmetros estimados dos semivariogramas, ajustados aos valores da massa seca de folhas (MSF), colmo (MSC) e material morto (MSMM) em pastagem de Urochloa brizantha cv. Marandu

\begin{tabular}{|c|c|c|c|c|c|c|}
\hline \multirow{2}{*}{ Tamanho da amostra } & \multirow{2}{*}{ Modelo } & \multicolumn{3}{|c|}{ Parâmetro } & \multirow{2}{*}{$\mathrm{RMSE}^{4}$} & \multirow{2}{*}{$\mathrm{AIC}^{5}$} \\
\hline & & $\mathrm{C}_{0}{ }^{1}$ & $\mathrm{C}_{0}+\mathrm{C}^{2}$ & $\mathbf{A}^{3}$ & & \\
\hline \multicolumn{7}{|c|}{ MSF $^{6}$} \\
\hline 30 & Esférico & 0,00 & 961.90 & 56,65 & 177,00 & 118,90 \\
\hline 60 & Esférico & 0,00 & 1043,60 & 40,97 & 112,00 & 110,70 \\
\hline 90 & Esférico & 509,70 & 967,50 & 46,79 & 79,26 & 104,50 \\
\hline 120 & Esférico & 373,40 & 897,20 & 43,84 & 29,41 & 86,64 \\
\hline 150 & Esférico & 448,90 & 800,20 & 46,38 & 21,24 & 80,78 \\
\hline \multicolumn{7}{|c|}{$\mathrm{MSC}^{7}$} \\
\hline 30 & Gaussiano & 0,00 & 379,90 & 13,18 & 33,34 & 88,90 \\
\hline 60 & Gaussiano & 185,60 & 401,30 & 15,47 & 33,15 & 88,80 \\
\hline 90 & Esférico & 180,00 & 446,80 & 33,18 & 41,16 & 92,69 \\
\hline 120 & Gaussiano & 275,60 & 419,50 & 15,84 & 28,08 & 85,81 \\
\hline 150 & Esférico & 241,00 & 400,30 & 40,73 & 23,76 & 82,80 \\
\hline \multicolumn{7}{|c|}{$\mathrm{MSMM}^{8}$} \\
\hline 30 & Esférico & 173,80 & 563,00 & 41,76 & 50,56 & 96,38 \\
\hline 60 & Gaussiano & 0,00 & 770,20 & 15,55 & 41,36 & 92,78 \\
\hline 90 & Esférico & 480,00 & 687,40 & 36,57 & 42,90 & 93,44 \\
\hline 120 & Esférico & 425,40 & 600,10 & 41,56 & 14,86 & 74,35 \\
\hline 150 & Esférico & 420,90 & 551,70 & 38,54 & 14,85 & 74,34 \\
\hline
\end{tabular}

${ }^{(1)} \mathrm{C}_{0}$ : efeito pepita; ${ }^{(2)} \mathrm{C}_{0}+\mathrm{C}$ : patamar; ${ }^{(3)} \mathrm{A}$ : alcance; ${ }^{(4)} \mathrm{RMSE}$ : raiz quadrada do erro quadrático médio; ${ }^{(5)} \mathrm{AIC}$ : Critério de Akaike, ${ }^{(6)}$ MSF: massa seca de folhas, ${ }^{(7)}$ MSC: massa seca de colmo, ${ }^{(8)}$ MSMM: massa seca de material morto.

\section{REVENG 406-416p.}


médio (RMSE) e o critério de Akaike (AIC) da MSFV, observou-se que à medida que o número de amostras aumenta o ajuste do semivariograma melhora e, consequentemente, a exatidão dos mapas construídos. Observou-se que para todas as características agronômicas do capim Marandu os tamanhos de amostras de 120 e 150 apresentaram valores de RMSE e AIC bem próximos e mais baixos em ralação aos demais números de amostras. Nas variáveis MSC e MSMM também ocorreram melhorias na precisão do ajuste do semivariograma conforme aumentava o número de amostras, porém, no tamanho de amostra igual a 90, observou-se perda de exatidão em relação aos demais planos amostrais.

A partir dos modelos obtidos para os semivariogramas ajustados para cada variável do estudo, estimaram-se os valores das variáveis para locais não amostrados por meio do método de interpolação de krigagem ordinária. Com os valores estimados, foi possível construir mapas de contorno que expressaram a variabilidade das características avaliadas em função do número de amostras utilizadas. As superfícies de krigagem (Figura 2, 3 e 4) ilustram os padrões gerais dos semivariogramas discutidos acima, permitindo visualizar os arranjos da distribuição espacial da disponibilidade de massa seca da gramínea da pastagem investigada.

O nível de disponibilidade de massa seca de folhas em pastagens, tal como topografia e localização de aguadas, é indutor para a escolha de um sítio de pastejo pelos animais (TREVISAN et al., 2005). Desta forma, mapas que predizem a oferta de forragem, espacialmente, permitem ao manejador da pastagem saber como, quando e onde os animais realizariam o pastoreio (MEZZALIRA et al., 2013). Diante disso, pode-se conhecer o comportamento de pastejo dos animais e criar estratégias que garanta que o desempenho desses não seja interferido pela presença ou ausência da

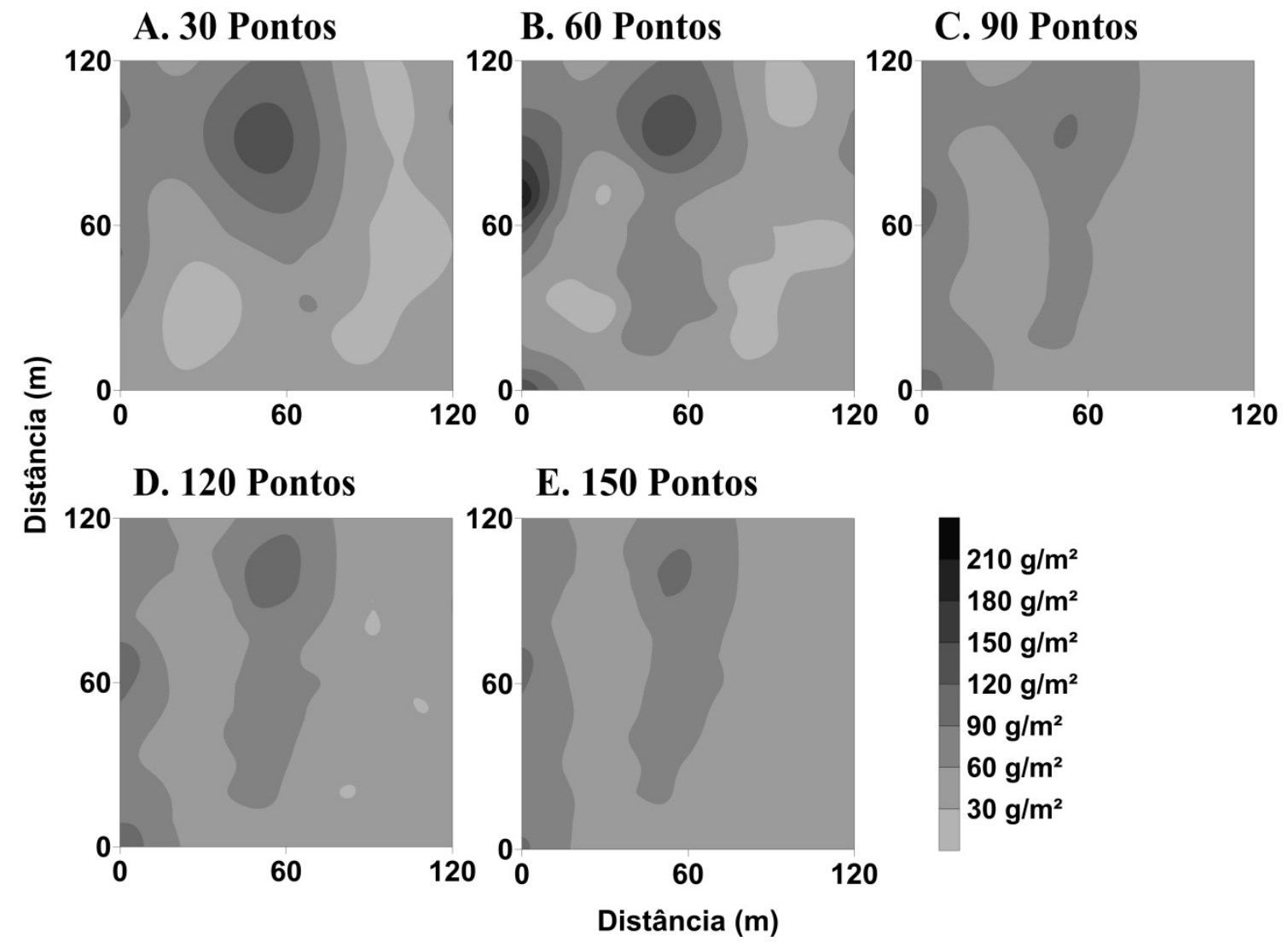

Figura 2. Mapas de contorno da distribuição espacial da produção de massa seca de folhas em pastagem de Urochloa brizantha cv. Marandu, com base no número de pontos amostrais utilizados. 


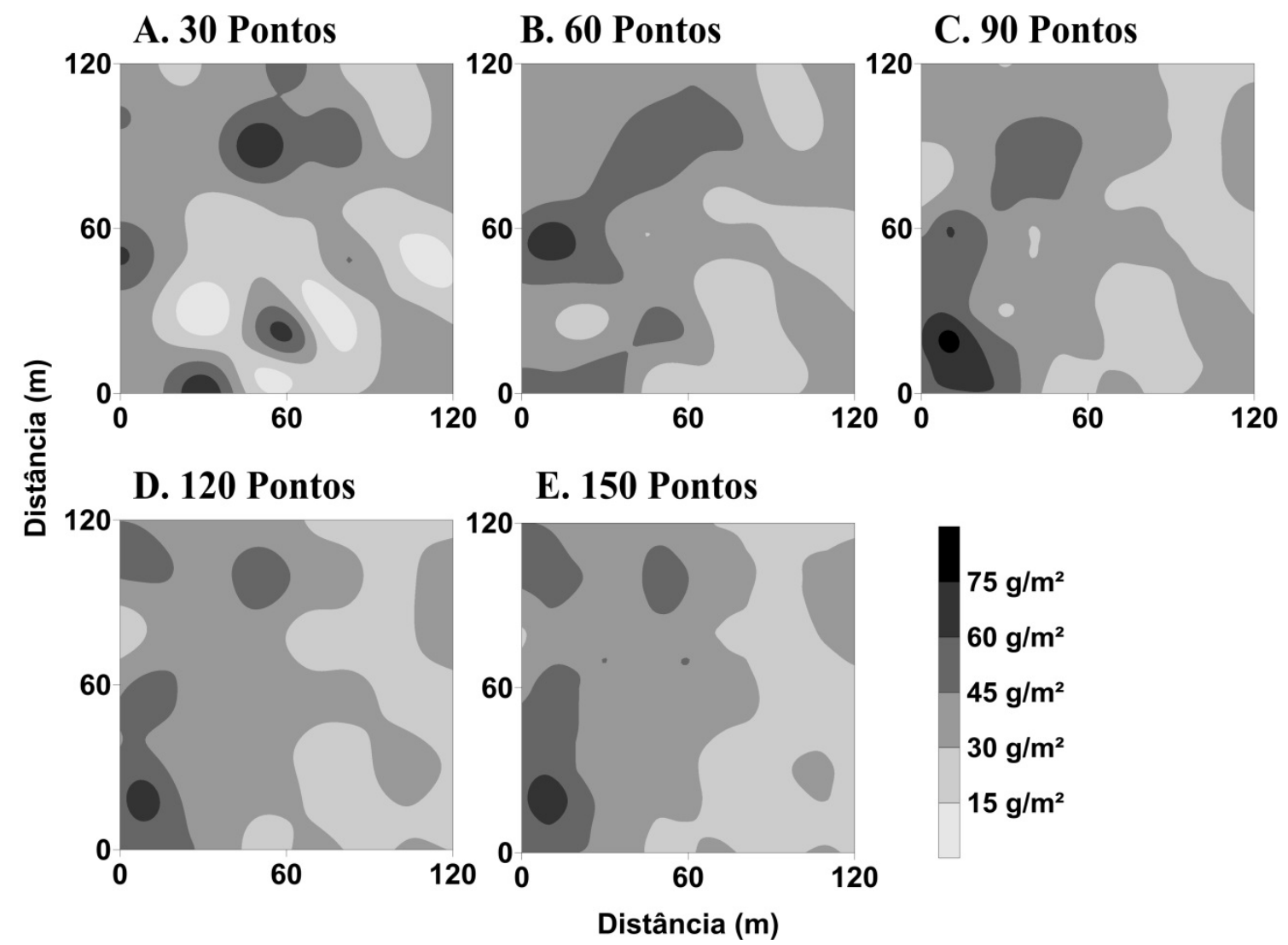

Figura 3. Mapas de contorno da distribuição espacial da produção de massa seca de colmo em pastagem de Urochloa brizantha cv. Marandu, com base no número de pontos amostrais utilizados.

variabilidade espacial da vegetação no pasto. $\mathrm{Na}$ Figura 2, notam-se diferentes arranjos espaciais da produção de massa seca de lâminas foliares nos planos amostrais com 30, 60 e 90 pontos em relação aos planos com 120 e 150 pontos amostrais. Neste contexto, a gestão dos padrões de pastejo dos animais será ineficiente frente a essas predições com números de amostras inferiores a 120 pontos.

Em geral os herbívoros em pastejo buscam selecionar plantas e seus componentes morfológicos para otimizar o consumo de nutriente, o gasto energético e evitar a ingestão de fitoquímicos prejudiciais a saúde (CARVALHO, 2013). Neste sentido, conhecer a distribuição espacial de oferta de massa seca de colmo, que normalmente possui menor digestibilidade e concentração de nutriente, pode apoiar às ações de manejo da pastagem, que garantam as metas de pastejo e desempenho dos animais. Além disso, essa conjuntura espacial permite que o gestor aprenda e compreenda as necessidades comportamentais dos animais em pastejo.
Observou-se que os mapas da produção de massa seca de folhas, colmo e material morto, que foram interpolados utilizando 120 e 150 pontos amostrais, mantiveram padrões semelhantes (Figuras 2, 3 e 4), apresentando os menores valores de RMSE e AIC. Mapas interpolados por meio da krigagem ordinária, que caracterizam espacialmente os atributos do solo, são obtidos com exatidão quando o número de pontos de coleta não é inferior a 100 (SOUZA et al., 2014). Sob essa ótica, as respostas do presente estudo indicam que a mesma recomendação, de coleta mínima de 100 pontos, deve ser adotada para as características de produção de massa de forragem da cultivar Marandu do Urochloa brizantha. Este comportamento da variabilidade espacial da gramínea é coerente, pois os níveis de disponibilidade de biomassa da pastagem e sua variação horizontal se correlacionam com a distribuição espacial dos atributos intrínsecos do solo (GREGO et al., 2012; SALTO \& CARVALHO, 2007).

A existência de variabilidade espacial da

\section{REVENG 406-416p.}

ENGENHARIA NA AGRICULTURA, VIÇOSA - MG, V.24 N.5, SETEMBRO / OUTUBRO 2016 


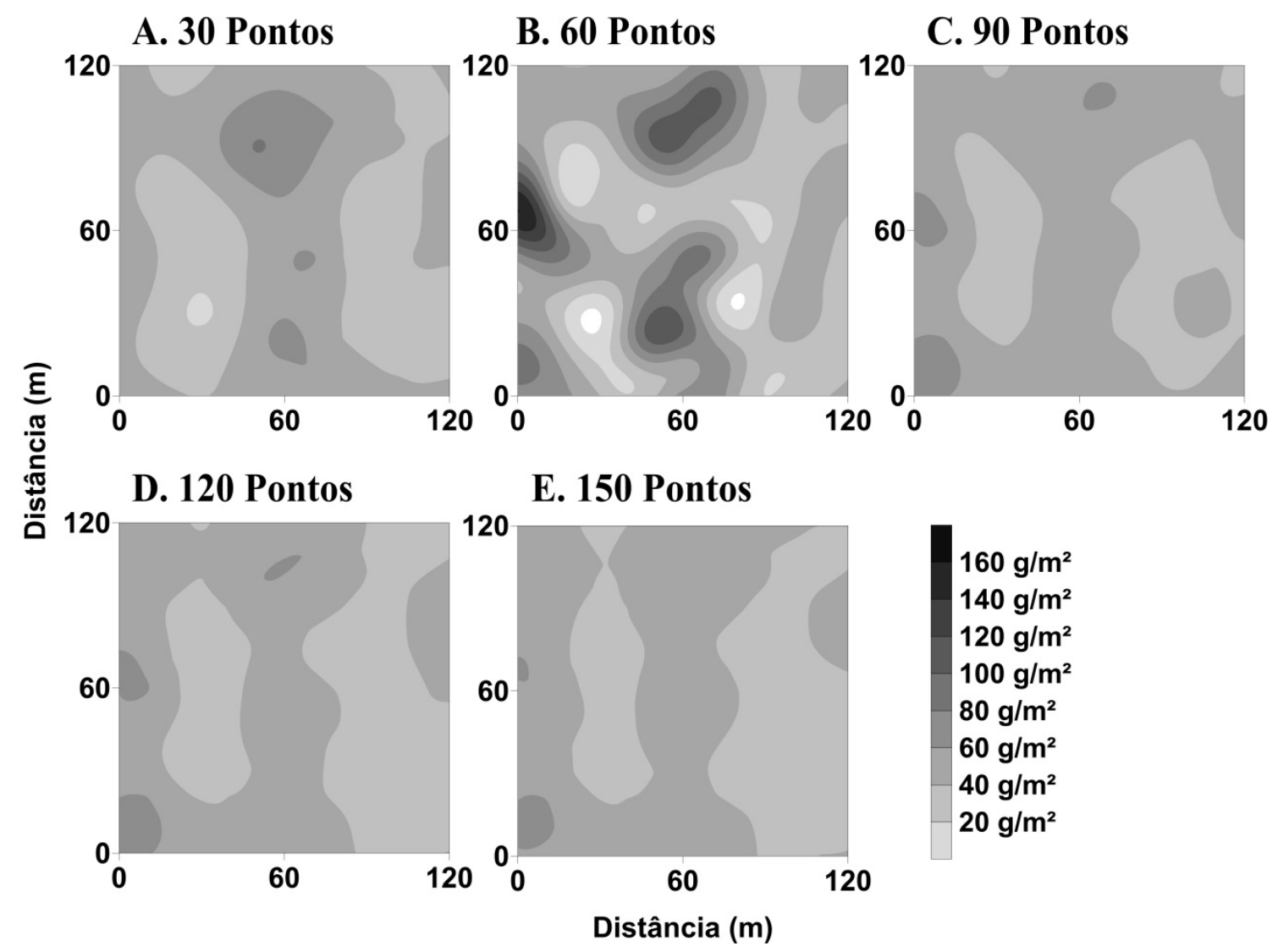

Figura 4. Mapas de contorno da distribuição espacial da produção de massa seca de material morto em pastagem de Urochloa brizantha cv. Marandu, com base no número de pontos amostrais utilizados.

biomassa vegetal em pastos gera modificações nos padrões de deslocamento e procura de forragem pelos animais (GONÇALVES et al., 2009). Com isso, conjectura-se que as ferramentas da geoestatística possam elucidar essa relação de causa e efeito entre estrutura espacial do dossel e padrões de pastejo dos animais. Ademais, a amostragem de biomassa da gramínea e a separação dos seus componentes morfológicos, para caracterizar a variação horizontal, são demorados e pouco eficientes, em relação às rotinas de uma propriedade rural. Nesse sentido, métodos indiretos que utilizam características descritoras que se associam fortemente com a massa de forragem e seus componentes morfológicos devem ser adotadas para inferir a variabilidade espacial. Assim, torna-se oportuno recomendar o desenvolvimento de detecções automáticas para tornar a rotina eficaz, prática, menos onerosae que podem ser relacionadas com outras variáveis tais como a biomassa disponível e a cobertura do solo.
Diante das predições exposta, realizou-se a mensuração das áreas de pastagem ocupadas por cada intervalo de disponibilidade de massa seca dos componentes morfológicos da gramínea para detectar as diferenças em função do tamanho das amostras. Assim, os valores das áreas $\left(\mathrm{m}^{2}\right)$, de oferta de MSF, MSC e MSMM, foram bem estreitos quando essas foram interpoladas com tamanhos de amostras com 120 e 150 pontos (Quadro 3), corroborando assim, com os mapas ilustrados anteriormente (Figuras 2, 3 e 4).

Vislumbra-se que estimativas precisas, por meio da modelagem variográfica, permitem compreender a estrutura horizontal do pasto, bem como, o qual terá influencia sobre o comportamento ingestivo e desempenho dos animais. Diante disso, a robustez dos ajustes dos semivariogramas, que caracterizam a distribuição espacial da vegetação, é imprescindível para estimar e explicar os padrões de uso da pastagem pelos animais em ecossistema pastoril. 
Quadro 3. Classes de disponibilidade de massa seca de folhas (MSF), colmo (MSC) e material morto (MSMM) e suas respectivas áreas na pastagem de Urochloa brizantha cv. Marandu, em função do número de pontos amostrais

\begin{tabular}{|c|c|c|c|c|c|}
\hline \multirow{2}{*}{ Intervalo $\left(\mathrm{g} \mathrm{m}^{-2}\right)$} & \multicolumn{5}{|c|}{ Tamanho da amostra } \\
\hline & 30 & 60 & 90 & 120 & 150 \\
\hline \multicolumn{6}{|c|}{$\mathrm{MSF}^{1}$} \\
\hline $0-30$ & 2771,37 & 1772,48 & 0,00 & 82,20 & 0,00 \\
\hline $30-60$ & 6613,48 & 7184,68 & 9317,35 & 9446,89 & 9513,88 \\
\hline $60-90$ & 3168,31 & 3580,95 & 4885,32 & 4279,39 & 4673,51 \\
\hline $90-120$ & 1412,98 & 1249,98 & 197,33 & 591,52 & 212,61 \\
\hline $120-150$ & 433,85 & 509,59 & 0,00 & 0,00 & 0,00 \\
\hline $150-180$ & 0,00 & 75,78 & 0,00 & 0,00 & 0,00 \\
\hline $180-210$ & 0,00 & 26,55 & 0,00 & 0,00 & 0,00 \\
\hline \multicolumn{6}{|c|}{$\mathrm{MSC}^{2}$} \\
\hline $0-15$ & 969,84 & 0,00 & 0,00 & 0,00 & 0,00 \\
\hline $15-30$ & 4554,42 & 3411,23 & 4107,21 & 4636,72 & 4771,33 \\
\hline $30-45$ & 6886,55 & 8145,89 & 7826,40 & 7874,84 & 7388,91 \\
\hline $45-60$ & 1636,01 & 2648,04 & 1937,67 & 1745,62 & 2043,97 \\
\hline $60-75$ & 353,18 & 194,84 & 528,72 & 142,82 & 195,79 \\
\hline \multicolumn{6}{|c|}{$\mathrm{MSMM}^{3}$} \\
\hline $0-20$ & 88,08 & 1154,82 & 0,00 & 0,00 & 0,00 \\
\hline $20-40$ & 5830,68 & 4833,84 & 4496,58 & 6200,96 & 6132,67 \\
\hline $40-60$ & 7167,24 & 4650,15 & 9306,94 & 7702,96 & 8018,26 \\
\hline $60-80$ & 1295,74 & 1871,75 & 596,48 & 496,08 & 249,07 \\
\hline $80-100$ & 18,26 & 1153,92 & 0,00 & 0,00 & 0,00 \\
\hline $100-120$ & 0,00 & 574,71 & 0,00 & 0,00 & 0,00 \\
\hline $120-140$ & 0,00 & 87,45 & 0,00 & 0,00 & 0,00 \\
\hline $140-160$ & 0,00 & 73,36 & 0,00 & 0,00 & 0,00 \\
\hline
\end{tabular}

${ }^{(1)}$ MSF: massa seca de folhas, ${ }^{(2)}$ MSC: massa seca de colmo, ${ }^{(3)}$ MSMM: massa seca de material morto.

\section{CONCLUSÕES}

- A variabilidade espacial das características de produção da gramínea foi caracterizada em todos os planos amostrais utilizados.

- Os melhores ajustes dos semivariogramas foram observados quando se utilizou 120 e 150 pontos de amostra.

- Deve-se utilizar no mínimo 120 pontos de amostras para realizar estudos da variabilidade espacial das características de produção de massa em pastagens de Urochloa brizantha $\mathrm{cv}$. Marandu.

\section{AGRADECIMENTOS}

Ao IFTO pelo apoia a pesquisa e ao $\mathrm{CNPq}$ pela concessão de bolsa de PIBIC-EM.

\section{REFERÊNCIAS BIBLIOGRÁFICAS}

CARVALHO, P.C.F. Harry stobbs memorial lecture: can grazing behavior support innovations

\section{REVENG 406-416p.}


in grassland management?. Tropical Grasslands

- ForrajesTropicales. v.1, n.2, p.137-155, 2013.

EMPRESA BRASILEIRA DE PESQUISA AGROPECUÁRIA - EMBRAPA. Sistema brasileiro de classificação de solos. Centro Nacional de Pesquisa de Solos. Rio de Janeiro, 2006. 306p.

GOLDEN SOFTWARE. Surfer for Windows version 8.0. Colorado: Golden, 2002.

GONÇALVES, E.N.; CARVALHO, P.C.F.; DEVINCENZI, T.; LOPES, M.L.T.; FREITAS, F.K.; JACQUES, A.V.A. Relações planta-animal em ambiente pastoril heterogêneo: padrões de deslocamento e uso de estações alimentares. Revista Brasileira de Zootecnia. v.38, n.11, p.2121-2126, 2009.

GREGO, C.R.; RODRIGUES, C.A.G.; NOGUEIRA, S.F.; GIMENES, F.M.A.; OLIVEIRA, A. ALMEIDA, C.G.F.; FURTADO, A.L.S.; DEMARCHI, J.J.A.A. Variabilidade espacial do solo e da biomassa epígea de pastagem, identificada por meio de geostatística. Pesquisa Agropecuária Brasileira. v.47, n.9, p.1404-1412, 2012.

HIRATA, M. Herbage availability and utilisation in small-scale patches in a bahia grass (Paspalum notatum) pasture under cattle grazing. Tropical Grasslands, Austrália, v.36, n.1, p.13-23, 2002.

LANDIM, P.M.B. Sobre Geoestatística e mapas. TerræDidatica, v.2, n.1, p.19-33. 2006.

MATHERON, G. Principles of geostatistics. Economic Geology, v.58, n.8, p.1246-1266, 1963.

MEZZALIRA, J.C.; BREMM, C.; TRINDADE, J.K.D.; GONDA, H.L.; VIEIRA, P.C.; CARVALHO, P.C.F. Ingestive behaviour from the feeding station to patch level in heterogeneous environments. Journal of Animal Science Advances. v.3, n.12, p.613-623, 2013.

PALHANO, A.L.; CARVALHO, P.C.F.;
DITTRICH, J.R.; MORAES, A.; SILVA, S.C.; MONTEIRO, A.L.G. Padrões de deslocamento e procura por forragem de novilhas leiteiras em pastagem de capim-mombaça. Revista Brasileira de Zootecnia, v.35, n.6, p.2253-2259, 2006.

PÁSCOA, A.G. COSTA, M.J.R.P. Aplicação dos sistemas de informação geográfica para definição de estratégias de manejo de bovinos nas pastagens. Revista Brasileira de Zootecnia. v.36, Supl., p.45-51, 2007.

PAULA NETO, J.J.; ALEXANDRINO, E.; SANTOS, A.C.; MENDES FILHO, G.O.; SILVA, D.P.; MELO, J.C. Distribuição espacial da altura do dossel e efeito sobre a cobertura do solo em pastos mantidos em lotação contínua. Bioscience Journal. v.30, n.5, p.650-658, 2014. Supl 2.

SALTON, J.C.; CARVALHO, P.C.F. Heterogeneidade da pastagem - causas e consequências. Dourados: Embrapa Agropecuária Oeste. 2007. 41p.

SILVA NETO, S.P.; SANTOS, A.C.; LIMA LEITE, R.L.; DIM, V.P.; NEVES NETO, D.N.; CRUZ, R.S. Dependência espacial em levantamentos do estoque de carbono em áreas de pastagens de Brachiaria brizantha cv. Marandu. Acta Amazônica. v.42, n.4, p.547-556, 2012.

SILVA NETO, S.P.; SILVA, R.G.; SANTOS, A.C.; GAMA, F.R.; GUERRA, M.S.S.; BRITO, M.J.D. Padrões espaciais de deposição de fezes por bovinos de corte em áreas de pastagem. Revista Brasileira de Saúde e Produção Animal. v.12, n.2, p.538-550, 2011a.

SILVA NETO, S.P.; SANTOS, A.C.; LIMA LEITE, R.L.; DIM, V.P.; CRUZ, R.S.; PEDRICO, A.; NEVES NETO, D.N. Análise espacial de parâmetros da fertilidade do solo em região de ecótono sob diferentes usos e manejos. Semina: Ciências Agrárias. v.32, n.2, p.541-552, 2011 b.

SOUZA, Z.M.; SOUZA, G.S.; MARQUES JÚNIOR, J.; PEREIRA, G.T. Número de amostras na análise geoestatística e na krigagem de mapas 
de atributos do solo. Ciência Rural. v.44, n.2, p.261-268, 2014.

TREVISAN, N.B.; QUADROS, F.L.F.; SILVA, A.C.F.; BANDINELLI, D.G.; MARTINS, C.E.N. Efeito da estrutura de uma pastagem hibernal sobre o comportamento de pastejo de novilhos de corte. Revista Brasileira de Zootecnia. v.34, n.3, p.774780, 2005.

VIEIRA, S.R. Geoestatística em estudos de variabilidade espacial do solo. In: NOVAIS, R.F.;
ALVAREZ, V.H.; SCHAEFER, C.E.G.R. (Eds.) Tópicos em ciência do solo. Viçosa: Sociedade Brasileira de Ciência do Solo. v.1, p.1-53, 2000.

WARRICK A.W. \& NIELSEN, D.R. Spatial variability of soil physical properties in the field. In: HILLEL, D. (Ed.). Application of soil physics. New York: Academic Press, 1980.

WEBSTER, R.; OLIVER, M.A. Sample adequately to estimate variograms of soil properties. Journal of Soil Science, v.43, n.1, p.177-192, 1992. 